\title{
Erratum to: Sarcopenic overweight is associated with early acute limiting toxicity of anti-PD1 checkpoint inhibitors in melanoma patients
}

\author{
Valentine Heidelberger ${ }^{1}$ - François Goldwasser ${ }^{1}$ • Nora Kramkimel ${ }^{2}$ - Anne Jouinot ${ }^{1}$. \\ Olivier Huillard $^{1}$. Pascaline Boudou-Rouquette ${ }^{1} \cdot$ Johan Chanal $^{2}$. \\ Jennifer Arrondeau ${ }^{1}$ - Nathalie Franck ${ }^{2}$ - Jérôme Alexandre ${ }^{1} \cdot$ Benoît Blanchet $^{3}$. \\ Karen Leroy ${ }^{4}$. Marie-Françoise Avril ${ }^{2} \cdot$ Nicolas Dupin $^{2} \cdot$ Sélim Aractingi ${ }^{2}$
}

Published online: 9 June 2017

(C) Springer Science+Business Media New York 2017

Erratum to: Invest New Drugs 2017

DOI 10.1007/s10637-017-0464-x

In the original published version of this paper, the authors would like to note that first names and last names have been reversed in the list of authors. The actual list is shown above. The original article was corrected.

The online version of the original article can be found at http://dx.doi.org/ 10.1007/s10637-017-0464-x

François Goldwasser

francois.goldwasser@aphp.fr

1 Department of Medical Oncology, CERTIM Group, Cochin Port-Royal Hospital, AP-HP, University Paris Descartes, 123 Bd Port-Royal, 75679 Paris Cedex 14, France

2 Department of Dermatology, CERTIM Group, Cochin Port-Royal Hospital, AP-HP, University Paris Descartes, 123 Bd Port-Royal, 75 679 Paris Cedex 14, France

3 Department of Pharmacokinetics and Pharmacochemistry, CERTIM Group, Cochin Port-Royal Hospital, AP-HP, University Paris Descartes, 123 Bd Port-Royal, 75679 Paris Cedex 14, France

4 Department of Biochemistry and Molecular Biology, CERTIM Group, Cochin Port-Royal Hospital, AP-HP, University Paris Descartes, 123 Bd Port-Royal, 75679 Paris Cedex 14, France 